\title{
Pelatihan Analisis Usaha Pada Klaster Batik Semarang
}

\author{
${ }^{1}$ Sri Yuni Widowati, ${ }^{2}$ Wyati Saddewisasi, ${ }^{3}$ Teguh Ariefiantoro, \\ ${ }^{2}$ Aprih Santoso \\ Program Studi Manajemen Universitas Semarang \\ Email: aprihsantoso@usm.ac.id
}

\begin{abstract}
The purpose of the training is to increase understanding and knowledge of planning through business analysis, so that batik business is expected to increasingly be able to increase the profits of entrepreneurs in the batik cluster. Training implementation methods are: counseling methods (lectures, questions and answers) and discussions between participants. Evaluation of training activities is carried out with pre-test and post-test. The results of the training are that participants are able to know and understand business development techniques; able to know and understand about how to make a business feasibility study and measure strengths, weaknesses, opportunities, and business threats (SWOT Analysis). This can be seen from the pre-test results distributed by the training team. The conclusions of this training include the members of the batik cluster who have been able to increase knowledge about business development techniques and can conduct business feasibility studies, measure strengths, weaknesses, opportunities, and business threats (SWOT Analysis) as well as increasing motivation to run their businesses.
\end{abstract}

Keywords: Business; SWOT; motivation; the profit

\section{Pendahuluan}

Pengusaha batik di kota Semarang, sebagian besar menjalankan usahanya secara tradisional (25 orang) dan sebagian kecil (3 orang) sudah cukup maju. Mereka mulai menyadari akan arti penting kebersamaan untuk memajukan usahanya. Dengan difasilitasi dari Bappeda (Badan Perencanaan Pembangunan Daerah) Kota Semarang melalui lembaga FEDEP (Forum for Economic Development and Employment Promotion) dan berlatar belakang dari kesamaan usaha (bergerak di bidang perbatikan) akhirnya dibentuklah klaster batik pada bulan Juli 2009. Harapan dari pembentukan klaster batik 
ini adalah agar masalah perbatikan dari proses awal sampai proses akhir pembatikan maupun pemasaran dapat ditangani dengan baik sesuai dengan filosofi klaster yaitu: pengintegrasian kegiatan usaha dari hulu sampai hilir.

Dengan adanya klaster batik, diharapkan masalah-masalah yang ada dapat diatasi, karena para pengusaha dapat melakukan tranfer teknologi maupun tranfer ilmu melalui kegiatan "Rembug Klaster” yang diagendakan 2 bulan sekali. Saat awal pembentukan, tempat pertemuan selalu berpindah dari anggota yang satu ke anggota yang lain karena belum adanya tempat pertemuan yang digunakan secara menetap, bahkan lebih sering bertempat di Bappeda kota Semarang. Salah satu tempat yang saat ini mulai digunakan untuk pertemuan rutin adalah gedung kesenian "SOBOKARTI" yang ada di jalan Dr. Cipto. Pembentukan klaster batik di kota Semarang baru seumur jagung sehingga banyak hal yang harus dilakukan agar klaster dapat berjalan sesuai yang diharapkan para pengusaha batik. Untuk melakukan pembenahan ini tentunya tidak terlepas dari pelaksanaan proses manajemen yang baik dari klaster. Pembenahan sudah dilakukan secara perlahan pada klaster batik, salah satunya dengan pembentukan pengurus disertai dengan pembagian tugas dari masing-masing anggota, selain itu para anggota juga sudah diperkenalkan dengan penyusunan laparan keuangan secara sederhana dan bagaimana pula mengawali kegiatan berkoperasi (Dilakukan pada kegiatan pengabdian sebelumnya).

\section{Tabel 1. Rata-rata Omset Penjualan Pengusaha Pada Klaster Batik Semarang}

\begin{tabular}{|c|l|c|c|}
\hline No & \multicolumn{1}{|c|}{ Omset penjualan /bulan } & $\begin{array}{c}\text { Jumlah } \\
\text { pengusaha }\end{array}$ & $\begin{array}{c}\text { Persentase } \\
(\%)\end{array}$ \\
\hline 1 & $<$ Rp 2.000.000 & 19 & 69 \\
\hline 2 & Rp. 2.000.000-Rp. 4.000.000 & 6 & 21 \\
\hline 3 & $>$ Rp.4.000.000 & 3 & 10 \\
\hline \multicolumn{2}{|c|}{ Jumlah } & 28 & 100 \\
\hline
\end{tabular}

Sumber: Data primer yang sudah diolah, 2017 
Saat ini, salah satu permasalahan yang dihadapi adalah terkait dengan analisis usaha. Selama ini usaha dilakukan secraca alamiah tidak pernah melakukan perencanaan di bidang: modal/ investasi, biaya operasional, pemasukan perbulan, prediksi keuntungan, dan balik modal/ BEP (impas). Secara umum dengan menjalankan usaha seperti ini, omset rata perbulan pengusaha masih jauh dari harapan (Lihat tabel.1) karena sebagian besar masih beromset dibawah Rp. 2.000 .000 (69\%). Dengan kondisi tersebut harus juga dipikirkan bagaimana merencanakan usahanya. Analisis usaha mutlak dilakukan bila seseorang hendak memulai usaha. Analisis usaha dilakukan untuk mengukur atau menghitung apakah usaha tersebut menguntungkan atau merugikan. Analisis usaha memberi gambaran kepada peternak untuk melakukan perencanaan usaha. Dalam analisis usaha diperlukan beberapa asumsi dasar. Asumsi dasar dapat berubah sesuai dengan perkembangan waktu. Dengan melihat kondisi tersebut, maka tim pelatihan tergerak untuk melakukan pengabdian kepada masyarakat dengan mengadakan "Pelatihan Analisis Usaha". Dengan adanya analisis usaha, produk batik terutama yang dibuat oleh klaster Batik Semarang diharapkan dapat memperoleh keuntungan secara ekonomi dan omset penjualannya dapat meningkat.

Pelatihan ini merupakan bentuk nyata pengabdian kepada masyarakat yang berupa pembinaan kepada masyarakat, khususnya para anggota klaster Batik di kota Semarang. Pelatihan ini untuk meningkatkan pemahaman dan pengetahuan perencanaan melalui analisis usaha batik. Melalui pelatihan ini, diharapkan pengusaha batik semakin dapat meningkatkan keuntungan. Adapun kerangka pemecahan masalah pada kegiatan ini adalah dengan memberikan pelatihan terkait analisis usaha klaster batik di Kota Semarang Pelatihan tersebut merupakan bagian dari upaya untuk meningkatkan pemahaman dan pengetahuan anggota klaster batik, serta untuk meningkatkan keuntungan pengusaha pada klaster batik di kota Semarang. 
Pelatihan ini juga merupakan kegiatan pengabdian kepada masyarakat yang sejalan dengan upaya pemerintah daerah Kota Semarang dalam meningkatkan kompetensi Sumber Daya Manusia (SDM) UMKM khususnya SDM klaster batik.

Berdasarkan hal di atas, tujuan pelatihan adalah untuk meningkatkan pemahaman dan pengetahuan perencanaan melalui analisis usaha. Dengan adanya analisis usaha, produk batik terutama yang dibuat oleh klaster Batik Semarang diharapkan dapat memperoleh keuntungan secara ekonomi dan omset penjualannya dapat meningkat.

\section{Metode}

Metode yang diterapkan untuk mencapai pemecahan permasalahan klaster batik ini adalah metode pelatihan (ceramah, tanya jawab) dan diskusi antar peserta serta evaluasi yang dilaksanakan dengan pre-test dan post-test. Pre-test dimaksudkan untuk mengetahui sejauhmana pengetahuan para peserta tentang analisis usaha sebelum pelatihan dilakukan. Post-test bertujuan untuk mengetahui seberapa besar daya tanggap para anggota klaster batik terhadap materi yang diberikan. Kegiatan pelatihan ini memiliki tahapan pelaksanaanya melalui pelatihan analisis usaha. Pelatihan ini dilaksanakan dengan memberikan materi terkait perencanaan usaha di bidang : modal/ investasi, biaya operasional, pemasukan perbulan, prediksi keuntungan, dan balik modal/ BEP (impas). Pemberi materi yaitu Dra. Sri Yuni Widowati, MM., dan Drs. Aprih Santoso, MM. Narasumber dari setiap pelatihan yang terdiri dari pendidik akuntansi dan mempunyai pengalaman praktek di bidang akuntansi. Pelatihan ini dihadiri oleh 30 anggota klaster batik. Pelatihan ini bertempat di Fakultas Ekonomi Universitas Semarang. (2) Pelatihan Studi kelayakan bisnis melalui SWOT.

\section{Hasil dan Diskusi}

Pelatihan dengan tema 'Analisis Usaha Pada Klaster Batik Semarang, 
telah dilaksanakan tanggal 7 Maret 2017, bertempat di Fakultas Ekonomi Universitas Semarang Lantai 1. Peserta pelatihan adalah anggota klaster batik di kota Semarang dan dihadiri oleh 30 orang.
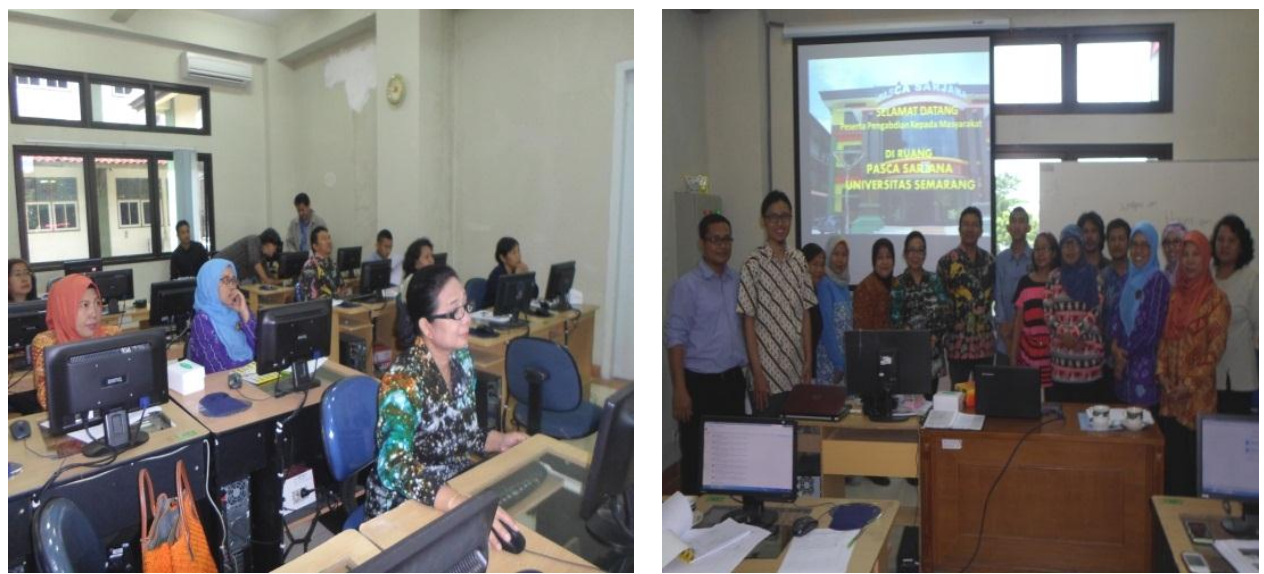

\section{Gambar 1. Pelatihan dengan tema Analisis Usaha Pada Klaster Batik Semarang (Sumber: Dokumentasi, 2017)}

Pelatihan ini dilaksanakan dengan memberikan materi terkait perencanaan usaha di bidang: modal/investasi, biaya operasional, pemasukan perbulan, prediksi keuntungan, dan balik modal/ BEP (impas). Pemberian materi diisi oleh Dra. Sri Yuni Widowati, MM., dan Drs. Aprih Santoso, MM (Dosen Manajemen Fakultas Ekonomi Universitas Semarang). Pelatihan ini juga memberi materi berupa pemberian pre test dan post test kepada para anggota klaster batik mengenai materi pelatihan. Pre-test dan post- test ini tidak dinilai tapi dilihat secara keseluruhan bagaimana para anggota klaster batik menyerap materi terkait dengan perencanaan usaha di bidang : modal/ investasi, biaya operasional, pemasukan perbulan, prediksi keuntungan, dan balik modal/ BEP (impas). Hasil dari pre test dan post test kebanyakan para anggota klaster batik memahami materi terkait dengan perencanaan usaha tersebut. 
Selain itu, diisi juga materi studi kelayakan bisnis melalui SWOT. Hal ini mendorong agar para anggota klaster batik termotivasi dan memiliki jiwa kewirausahaan. Output dari pelatihan materi studi kelayakan bisnis melalui SWOT ini dilihat dari hasil isian kuesioner. Hasil dari output ini kebanyakan mampu mengetahui dan memahami studi kelayakan bisnis. Berikut ini foto-foto kegiatan pelaksanaan pelatihan Analisis Usaha Pada Klaster Batik Di Kota Semarang. Foto menunjukkan penyampaian materi, dan evaluasi.

\section{Simpulan}

Simpulan pada kegiatan pelatihan analisis usaha pada klaster batik di Kota Semarang ini antara lain anggota klaster batik sudah mampu menambah pengetahuan tentang teknik pengembangan usaha dan dapat membuat studi kelayakan bisnis, mengukur kekuatan, kelemahan, peluang, dan ancama usaha (SWOT Analysis) serta semakin meningkat motivasinya dalam menjalankan usahanya.

\section{Daftar Referensi}

Ariawati, Ria Ratna. (2004). Usaha Kecil dan Kesempatan Kerja. Fakultas Ekonomi, Jakarta : UNIKOM.

Da Veiga, Cassia Rita Pereira: Da Veiga, Claudimar Pereira: and Duclos, Luiz Carlos. (2010). The Accuaracy Of Demand Forecast Models As a Critical Factor In The Financial Performance of The Industry, Future Studies Research Journal, Vol. 2, No. 2, Hal. 81-104

Diana Khairani Sofyan. (2013). Perencanaan dan Pengendalian Produksi, Edisi Pertama, Yogyakarta : Graha Ilmu

Dipta, I. Wayan. (2004). Membangun Jaringan Usaha Bagi Usaha Kecil dan Menengah. Jakarta.

Dun Steinhoff, John F.Burgess.(1993).Small Business Management Fundamentals 6 th ed.New York:McGrawhill Inc.

Eddy Herjanto, (1998), Manajemen Produksi dan Operasi, Jakarta :Grasindo 
Iwantono, Sutrisno. (2004). Pemikiran Tentang Arah Kebijakan Pemerintah Dalam Pengembangan Usaha Kecil dan Menengah. Jakarta.

Pangabean, Riana. (2004). Membangun Paradigma Baru Dalam Mengembangkan UKM. Jakarta.

Philip Kotler dan Keller, (2012), Marketing Management Edisi 14, Global Edition Pearson Prentice Hall

Suryana. (2006). Kewirausahaan. Jakarta : Salemba Empat

Taufiq, Muhammad. (2004). Strategi Pengembangan UKM Pada Era Otonomi Daerah dan Perdagangan Bebas. Jakarta.

Theresia Ochin Rosmaria Pasaribu dan Rossi Septy Wahyuni. (2014). Penentuan Metode Peramalan Sebagai Dasar Penentuan Tingkat Kebutuhan Persediaan Pengaman pada Produk Karet Remah SIR 20, Jurnal Prosiding Seminar Ilmiah Nasional Komputer dan Sistem Intelejen (KOMMIT 2014), Vol. 8, ISSN: 2302-3740.

T. Hani Handoko. (2011). Manajemen, Yogyakarta : BPFE

T. Hani Handoko. (2015). Dasar-dasar Manajemen Produksi dan Operasi, Cetakan ke-19, Yogyakarta : BPFE

Widhy Wahyani dan Achmad Syaichu. (2015). Penerapan Metode Peramalan Sebagai Alat Bantu Untuk Menentukan Perencanaan Produksi di PT. SKK, Vol. 13, No. 2, Hal. 115-228. 